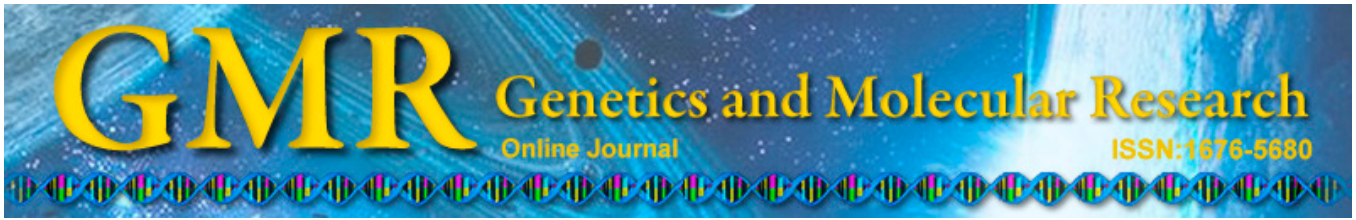

\title{
Population structure and genetic diversity in Gynaikothrips uzeli (Thysanoptera: Phlaeothripidae): is there a correlation between genetic and geographic proximity?
}

\author{
A.L.S. Mascarenhas ${ }^{1}$, A.M. Waldschmidt ${ }^{2}$ and J.C. Silva Jr. ${ }^{2}$ \\ ${ }^{1}$ Grupo de Pesquisa em Abelhas, \\ Instituto Nacional de Pesquisa da Amazônia, Manaus, AM, Brasil \\ ${ }^{2}$ Departamento de Ciências Biológicas, \\ Universidade Estadual do Sudoeste da Bahia, Jequié, BA, Brasil \\ Corresponding author: A.L.S. Mascarenhas \\ E-mail: andre_masc@yahoo.com.br \\ Genet. Mol. Res. 14 (3): 9793-9803 (2015) \\ Received January 31, 2015 \\ Accepted June 29, 2015 \\ Published August 19, 2015 \\ DOI http://dx.doi.org/10.4238/2015.August.19.12
}

\begin{abstract}
Gynaikothrips uzeli (Thysanoptera: Phlaeothripidae) is a minuscule insect species, which forms galls, is subsocial, and parthenogenetic. It is associated with Ficus benjamina L. (Moraceae) and has a pantropical occurrence. The paucity of genetic studies on the order Thysanoptera led us to use inter-simple sequence repeat molecular marker to assess intra- and inter-gall, as well as intraand inter-site, genetic variability and population structure of $G$. uzeli. Analyses indicated low genetic variability, probably related to haplodiploidy, genetic drift, the galling habit, and the low dispersal ability of G. uzeli. Populations were highly structured, with higher variation within populations than among them. Geographic distance does not appear to affect structure and genetic diversity, the latter being influenced by G. uzeli's bioecological traits, by numerous
\end{abstract}


introductions during a short period, and by a possible recent, common ancestry.

Key words: Ficus benjamina; Genetic variability; Haplodiploidy; Thrips; Heterozygosity; Inter-simple sequence repeat

\section{INTRODUCTION}

Gynaikothrips uzeli Zimmerman (1900) is a minuscule insect (2.5 to $3.6 \mathrm{~mm})$, which is phytophagous, forms galls (Retana-Salazar and Sánchez-Chacón, 2009), and shows subsocial behavior and parthenogenetic reproduction (Crespi, 1993; Kumm and Moritz, 2008). The species was originally described from southwestern Asia, but is distributed across the tropics, with records in the three Americas (Held et al., 2005; Cambero-Campos et al., 2010; Cavalleri et al., 2011). Its broad distribution can be explained, at least partly, by its very small size and cryptic behavior, which hamper its detection during international transport of agricultural products (Brunner et al., 2002).

While feeding on leaves of its host plant Ficus benjamina (Rosales: Moraceae), this species injects toxins that cause the leaves to curl and dry (Wolfenbarger, 1946). Such galls, when formed, serve not only as a food source, but also as shelter and protection against predators (Gonçalves-Alvim and Fernandes, 2001). The damage caused by G. uzeli on F. benjamina promotes the loss of its ornamental value, and determines the status of G. uzeli as a plague. The association between galling thrips and the host plant is a highly species-specific trophic strategy (Ananthakrishnan, 1993), such that the species G. uzeli and Gynaikothrips ficorum, which are morphologically distinguished only by the length of the posteroangular pair of setae on the pronotum (Priesner, 1939; Del Cãnizo, 1945; Retana-Salazar, 2006; Cambero-Campos et al., 2010), can also be distinguished by their host plants, F. benjamina and Ficus microcarpa, respectively (Mound et al., 1995; Dobbs and Boyd Jr., 2006). G. uzeli's life cycle is approximately 30 days long, with eight generations per year, on average, in humid subtropical climates (Farong et al., 1995). These features make this species important in the study of the evolution of social behavior in haplodiploid species, not only in terms of its ecological role, but also in terms of its genetics (Kranz et al., 2001).

Genetic markers are useful for the identification, characterization, and evaluation of genetic diversity. Among them, inter-simple sequence repeat (ISSR) molecular markers are remarkable for their use in the genetic characterization of plants, fungi, vertebrates, and insects (Wolfe, 2005). This method does not require previous isolates or specific DNA sequencing and allows the detection of polymorphism in DNA regions flanked by microsatellites (Zietkiewicz et al., 1994).

Studies on Thysanoptera have grown in number in recent years. However, only one study has been conducted that aimed to assess the genetic and population parameters of $G$. uzeli. Brito et al. (2012) evaluated the population structure and genetic diversity of six populations of G. uzeli from two states in Brazil, and found reduced genetic diversity and strong population structure, with higher genetic variation among populations than within them. However, some questions, such as the variability at lower levels (intra- and inter-galls) and the effect of distance, were not assessed. In this light, we used ISSR molecular markers in the current study to assess the genetic diversity and population structure of G. uzeli among individuals from the same gall (intra-gall variation), among individuals from different galls in the same tree (intergall variation), among individuals from different trees from the same site (intra-site variation), 
and among populations from different sites (inter-site variation). Then, we assessed the influence of geographic distance and behavioral aspects on the generation of genetic variability.

\section{MATERIAL AND METHODS}

\section{Collection and extraction of genomic DNA}

For the genomic analyses, we used adult $G$. uzeli found in the galls of $F$. benjamina. Collections were carried out in different ways according to each analysis: a) intra-galls: four trees were randomly selected (01, 03, 04, and 06; Figure 1$)$ and from each of them, a single gall was collected, from which ten individuals were sampled; b) inter-galls: two trees were randomly selected (03 and 09; Figure 1), from which eight galls were collected per tree, with two individuals collected per gall, for a total of 16 individuals per tree; c) intra-site: eleven trees in the city of Jequié (Bahia, Brazil) were sampled and, in each of them, three thrips, each from a different gall, were collected (Figure 1); and d) inter-sites: ten trees in each of six different cities (Figure 2) were sampled following the method described in c, for a total of 30 individuals per site.

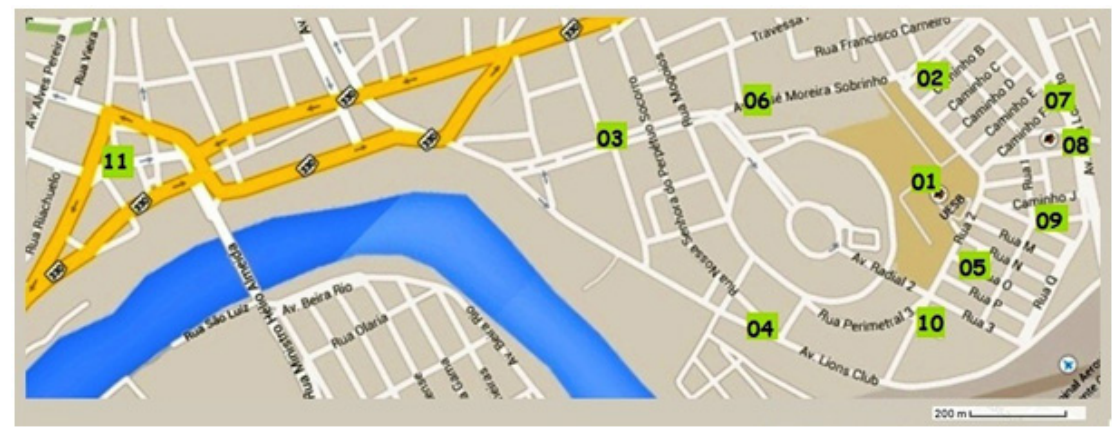

Figure 1. Collection points in the city of Jequié (Bahia, Brazil) of Gynaikothrips uzeli used for genomic analyses.

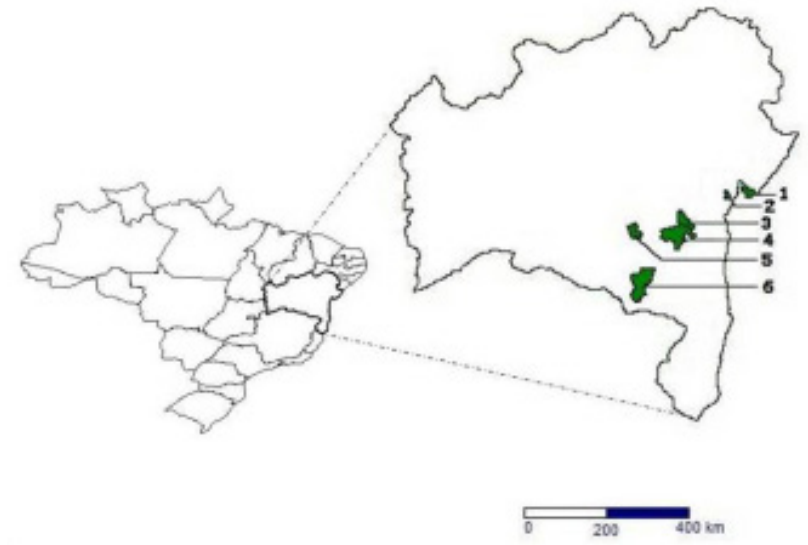

Figure 2. Collection sites of Gynaikothrips uzeli in Bahia, Brazil. 1: Salvador (SSA) - $12^{\circ} 59^{\prime} 06.1^{\prime \prime S}, 038^{\circ} 26^{\prime}$

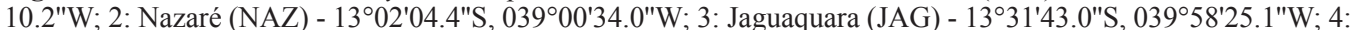

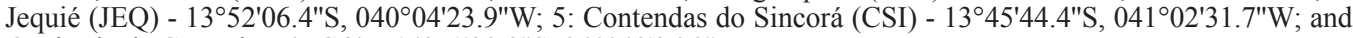
6: Vitória da Conquista (VCQ) - 1451'39.2"S, 04049'26.0"W. 
DNA extraction was carried on an individual basis and followed the protocol by Roberts (1998), with modifications (substitution of potassium acetate $8 \mathrm{M}$ with sodium acetate $8 \mathrm{M}$; longer centrifugation at 14,000 rpm instead of 16,000 rpm). The DNA was quantified in an L-Quant spectrophotometer.

\section{ISSR-PCR}

Initially, 39 ISSR primers (UBC series, University of British Columbia) were tested, and eleven of these were selected based on their definition, reproducibility, and number of generated bands (Table 1). Amplifications were carried out in a PTC-100 thermocycler (MJ Research Inc., Ramsey, MN, USA). Each reaction consisted of a total volume of $25 \mu \mathrm{L}$ containing $1 \mu \mathrm{L} 10 \mathrm{ng}$ genomic DNA, $2.0 \mu \mathrm{L}(200 \mu \mathrm{M}$ each) dNTPs, $0.5 \mathrm{U}$ Taq polymerase (Biotools), $1 \mu \mathrm{L} 50$ pmol primer, $2.5 \mu \mathrm{L} 10 \mathrm{X}$ buffer with $\mathrm{MgCl}_{2}$, and $18.4 \mu \mathrm{L}$ milli-Q water. The thermocycler was programmed for an initial denaturation step of 3 min at $94^{\circ} \mathrm{C}, 40$ cycles of $1 \mathrm{~min}$ at $92^{\circ} \mathrm{C}, 2 \mathrm{~min}$ at $53^{\circ} \mathrm{C}$ for the pairing of the primer, $2 \mathrm{~min}$ at $72^{\circ} \mathrm{C}$ for the elongation of fragments, and a final step of $7 \mathrm{~min}$ at $72^{\circ} \mathrm{C}$. Reactions included a negative control containing all the components except the genomic DNA, and a positive control containing already amplified DNA, in order to assess the reproducibility of the results.

Table 1. Selected inter-simple sequence repeat (ISSR) molecular markers, their respective sequences, and the
analysis in which they were used: 1 , intra-gall; 2 , inter-galls; 3 , intra-site; and 4; inter-sites.
\begin{tabular}{lll}
\hline Primers & Sequence $\left(5^{\prime} \rightarrow 3^{\prime}\right)$ & Analysis \\
\hline UBC 812 & GAG AGA GAG AGA GAG AA & 3 and 4 \\
UBC 825 & ACA CAC ACA CAC ACA CC & $1,2,3$, and 4 \\
UBC 825 b & ACA CAC ACA CAC ACA CT & 3 and 4 \\
UBC 827 & ACA CAC ACA CAC ACA CG & 1,3 , and 4 \\
UBC 836 & AGA GAG AGA GAG AGA GYA & 1 and 4 \\
UBC 846 & CAC ACA CAC ACA CAC ART & 4 \\
UBC 855 & ACA CAC ACA CAC ACA CYT & 3 and 4 \\
UBC 856 & ACA CAC ACA CAC ACA CYA & $1,2,3$, and 4 \\
UBC 884 & HBH AGA GAG AGA GAG AG & 2 \\
UBC 888 & GAT CAA GCT TNN NNN NAT GTG G & 3 and 4 \\
UBC 889 & CAT GGT GTT GGT CAT TGT TCC A & $1,2,3$, and 4 \\
\hline
\end{tabular}

The DNA fragments resulting from the amplification were separated by electrophoresis on a 1.2\% agarose gel and stained with Gelred (Biotium) diluted to 1:500. The amplified fragments were visualized under ultraviolet light and photographed under the L-Pix EX system (Loccus Biotecnologia, Cotia, SP, Brazil).

\section{Data analysis}

The products of amplification were coded according to the presence (1) or absence (0) of bands. The TFPGA v1.3 program (Miller, 1997) was used to estimate genetic diversity $\left(H_{\mathrm{E}}\right)$, the percentage of polymorphic loci, and Nei's (1978) genetic distance, as well as to construct a dendrogram using the unweighted pair group method with arithmetic mean (UPGMA). Analysis of molecular variance (AMOVA) (Excoffier et al., 1992) and an estimate of the index of structure among sites $\left(F_{\mathrm{ST}}\right)$ were carried out using the Arlequin v3.5.1.2 program (Excoffier 
et al., 2005). The statistical significance of the estimated structure index was tested with 1000 permutations.

Using a Bayesian approach, we further estimated genetic diversity and population structure using the HICKORY 1.1 software (Holsinger and Lewis, 2005), with the indices $H_{\mathrm{B}}$ and $\theta_{\mathrm{B}}$ being analogous to $H_{\mathrm{E}}$ and $F_{\mathrm{ST}}$, respectively. The analyses were carried out using four models chosen a priori (full model, $\mathrm{f}=0$ model, $\theta=0$ model, and $\mathrm{f}$ free model), with the best model being defined according to the lowest deviance information criterion value. A Markov Chain Monte Carlo was run for a total of 100,000 generations, with a burn-in of 20\%.

To test for a correlation between geographic and genetic distances among samples, we used a Mantel test based on Nei's genetic distance. This analysis was performed using the Arlequin v3.5.1.2 program (Excoffier et al., 2005), with 1000 permutations.

Bayesian inference was also used to assess population structure using STRUCTURE version 2.3.1 (Falush et al., 2007). The most probable number of populations (k) was estimated with an admixture model with correlated allele frequencies, without previous information on the origin of the population. The program performed 10,000 iterations, after a burn-in of 10,000 iterations, to assess population subdivision under $\mathrm{k}=1$ to 10 . Twenty replicates were carried out for each $\mathrm{k}$, in order to evaluate whether different runs could produce different likelihood values and to quantify variation in the probability. Individual proportions and admixture average (Q) for each population in each genetic cluster found by the program were recorded for the model. Results generated by STRUCTURE were later analyzed with STRUCTURE HARVESTER version 0.6.7 (Earl and vonHoldt, 2012), according to the method by Evanno et al. (2005).

Except for the analyses within galls, in which we only assessed genetic diversity and allelic clustering as generated by STRUCTURE HARVESTER, the remaining analyses involved all the above mentioned programs.

\section{RESULTS}

The data on genetic diversity $\left(H_{\mathrm{E}}\right.$ and $\left.H_{\mathrm{B}}\right)$, population structure $\left(F_{\mathrm{ST}}\right.$ and $\left.\theta_{\mathrm{B}}\right)$, and AMOVA are summarized in Table 2.

\begin{tabular}{|c|c|c|c|c|c|c|c|c|c|}
\hline \multirow[t]{2}{*}{ Analysis } & \multirow[t]{2}{*}{ Sample } & \multirow[t]{2}{*}{ No. of primers } & \multirow[t]{2}{*}{ No. of bands } & \multirow[t]{2}{*}{$H_{\mathrm{E}}$} & \multirow[t]{2}{*}{$H_{\mathrm{B}}$} & \multirow[t]{2}{*}{$F_{\mathrm{ST}}$} & \multirow[t]{2}{*}{$\theta_{\mathrm{B}}$} & \multicolumn{2}{|c|}{ Variance } \\
\hline & & & & & & & & Within & Among \\
\hline \multirow[t]{4}{*}{ Intra-gall } & Gall A & 5 & 30 & 0.1776 & - & - & - & - & - \\
\hline & Gall B & 5 & 53 & 0.1673 & - & - & - & - & - \\
\hline & Gall C & 5 & 39 & 0.168 & - & - & - & - & - \\
\hline & Gall D & 5 & 41 & 0.1315 & - & - & - & - & - \\
\hline \multirow[t]{2}{*}{ Inter-gall } & Tree A & 4 & 34 & 0.1614 & 0.1841 & 0.6613 & 0.5923 & $33.87 \%$ & $66.13 \%$ \\
\hline & Tree B & 4 & 30 & 0.1614 & 0.2254 & 0.5532 & 0.5644 & $44.68 \%$ & $55.32 \%$ \\
\hline Intra-site & 11 trees & 8 & 78 & 0.2057 & 0.2733 & 0.3206 & 0.4398 & $67.94 \%$ & $32.06 \%$ \\
\hline Inter-site & 6 cities & 10 & 112 & 0.2621 & 0.2349 & 0.3630 & 0.4797 & $63.69 \%$ & $36.31 \%$ \\
\hline
\end{tabular}

\section{Intra- and inter-gall analyses}

The plots generated with STRUCTURE for intra- and inter-gall analyses (Figure 3) revealed that all sets of alleles were shared among individuals in similar proportions. 


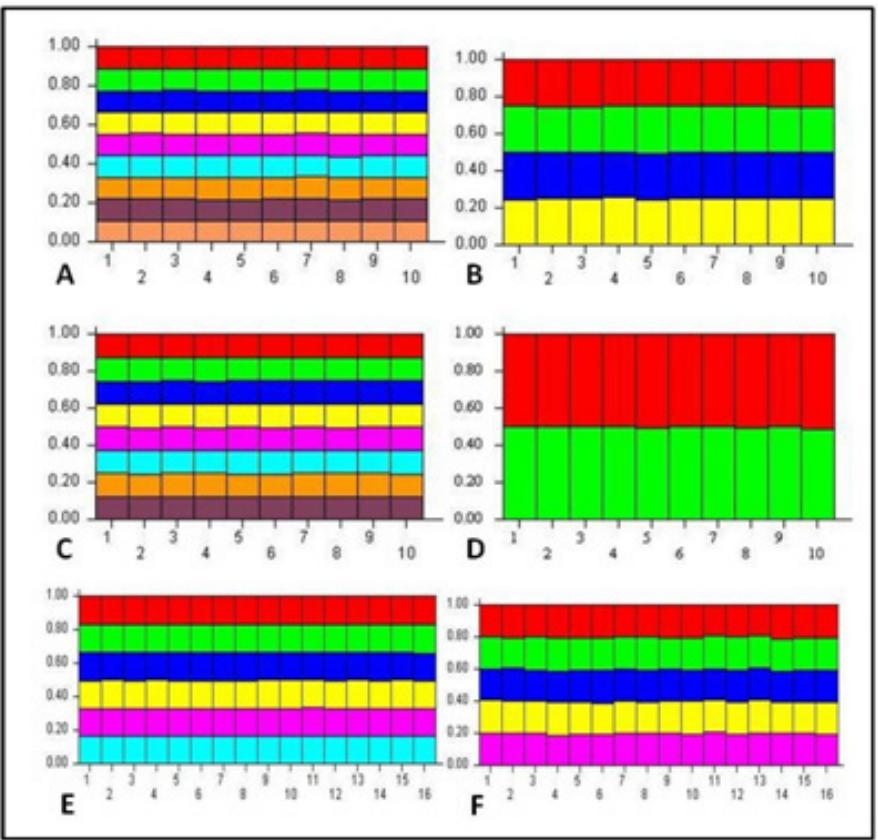

Figure 3. STRUCTURE plots showing allelic clustering in the intra- and inter-gall analyses. Intra-gall: A. gall A (tree 1); B. gall B (tree 3); C. gall C (tree 4); D. gall D (tree 6). Inter-gall: E. tree A (tree 3); F. tree B (tree 9).

\section{Intra-site analysis}

In the intra-site analysis (Figure 4A), the UPGMA dendrogram clustered the eleven $F$. benjamina trees into two groups, irrespective of the proximity between them. The plot generated by STRUCTURE revealed the formation of two groups of alleles shared by all individuals analyzed, although in different proportions (Figure 4B).

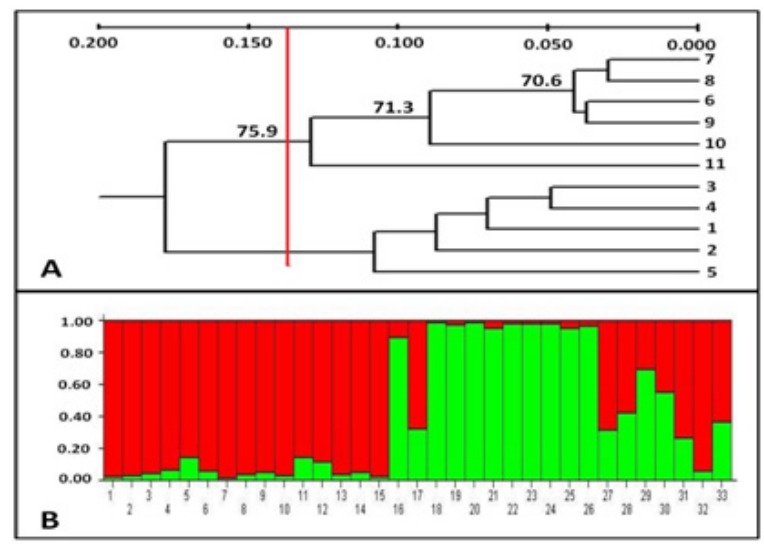

Figure 4. A. Dendrogram generated by the UPGMA method for analysis of intra-site population structure. The cutoff point was set at the median of the distances (Nei, 1978). Other bootstrap values lower than $55 \%$ are not shown. B. STRUCTURE HARVESTER plot showing grouping of alleles of the same 11 trees studied. 


\section{Inter-site analysis}

Pairwise genetic distance among populations (Table 3) indicated a smaller distance between the Salvador and Jaguaquara populations (0.0516) and a higher distance between the Salvador and Vitória da Conquista populations (0.1535).

Table 3. Nei's (1978) genetic distance among the different sites in the State of Bahia, Brazil, sampled for Gynaikothrips uzeli.

\begin{tabular}{lcccccc}
\hline & CSI & SSA & JAG & NAZ & JEQ & VCQ \\
\hline CSI & $* * * * *$ & & & & & \\
SSA & 0.0537 & $* * * * *$ & & & & \\
JAG & 0.0752 & 0.0516 & $* * * * *$ & & & \\
NAZ & 0.0864 & 0.0964 & 0.1039 & 0.0578 & $* * * * *$ & \\
JEQ & 0.0921 & 0.1023 & 0.1052 & 0.1518 & 0.0869 & $* * * * *$ \\
VCQ & 0.1498 & 0.1535 & 0.1338 & & \\
\hline
\end{tabular}

Contendas do Sincorá (CSI), Salvador (SSA), Jaguaquara (JAG), Nazaré (NAZ), Jequié (JEQ), and Vitória da Conquista (VCQ).

The dendrogram generated by the UPGMA method and the plot generated by STRUCTURE grouped the populations into three distinct clusters (Figure 5).

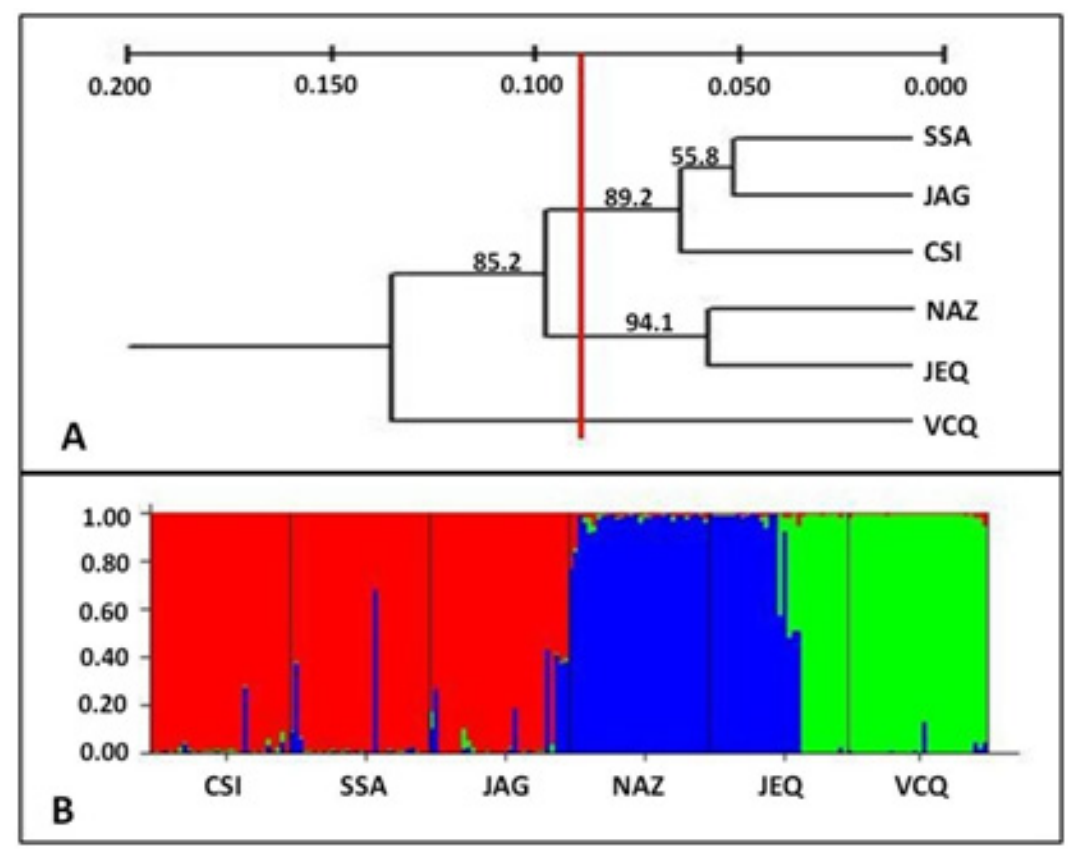

Figure 5. A. Dendrogram generated by UPGMA for the six populations of Gynaikothrips uzeli studied. The cut-off point was set at the median of the distances (Nei, 1978). B. STRUCTURE HARVESTER plot showing the same grouping of the six populations studied. 
AMOVA carried out under two hierarchical levels showed that $63.69 \%$ of the genetic variation is within populations, whereas $36.31 \%$ is among populations (Table 4 ).

Table 4. Analysis of molecular variance (AMOVA) for the six populations of Gynaikothrips uzeli considering
two hierarchical levels.
\begin{tabular}{lcccccc}
\hline Source of variation & d.f & SQ & Component of variance & Variance $(\%)$ & P value \\
\hline Among populations & 5 & 601.222 & 3.80679 & 36.31 & $<0.001$ \\
Within populations & 173 & 1155.421 & 6.67873 & 63.69 & $<0.001$ \\
Total & 178 & 1756.642 & 10.48552 & & \\
Fixation index $\left(F_{\text {ST }}\right)$ & 0.3630 & & & & \\
\hline
\end{tabular}

d.f. $=$ degrees of freedom; $S Q=$ sum of squares.

The Mantel test was not significant $(\mathrm{r}=0.3579 ; \mathrm{P}=0.125)$.

\section{DISCUSSION}

\section{Intra- and inter-gall analyses}

The intra- and inter-gall analyses were performed in principle as preliminary tests, with the goal of evaluating the existing polymorphism and defining the number of individuals to be sampled per gall, thus, we used fewer primers. However, the low levels of heterozygosity and the plots generated by STRUCTURE (Table 2 and Figure 3), along with data on the biology of the insect, allowed us to incorporate these analyses into the final study.

Our results reveal a high similarity among individuals from the same gall, as shown in the four galls analyzed, with all individuals sharing all allelic sets in similar proportions. The analysis between galls of a given tree also revealed low heterozygosity, highly structured populations, and a lower variation within galls than between them. Such data attest the high level of similarity among individuals from the same gall, in addition to helping to define the sampling scheme for each locality. Thus, we established that each gall could be represented by a single individual and that each tree could be represented by three galls.

\section{Intra-site analysis}

The analysis carried out with samples from the same site (Jequié; Figure 1), which aimed to assess genetic variability among neighboring trees, indicated a lack of correlation between similarity and proximity (Figure 4). Such data reinforce the theory that a series of introductions of $F$. benjamina (because of its use in urban arborization and ornamentation, $F$. benjamina was probably reintroduced many times) and the subsequent effects of genetic drift are the main components underlying the variability in populations of G. uzeli, such that each population in each tree has its own history of foundation, even though they share some alleles. Moreover, any physical barriers (walls, curves) are actual barriers to the dispersal of G. uzeli, even at short distances.

\section{Inter-site analysis}

Both the UPGMA dendrogram and STRUCTURE clustered the study sites into three 
groups: 1. Salvador, Jaguaquara, and Contendas do Sincorá; 2. Nazaré and Jequié, and 3. Vitória da Conquista (Figure 5). The way sites were clustered, together with the Mantel test, indicates that there is no relation between geographic and genetic proximity. However, genetic distance values (Table 3 ) do not necessarily inform about gene flow among populations, indicating genetic proximity that may be due to common ancestors. This would be likely considering the possibility that host plants originated from the same location.

AMOVA partitioned with hierarchical levels showed a high percentage of variation within populations (63.69\%), which differs from the results found by Brito et al. (2012), who used random amplified polymorphic DNA (RAPD) and found larger variation among populations than within them. The observed value from the current study points to the inexistence or restriction of gene flow among the different sites, and a possible increase of endogamy within them. The low dispersal capacity of G. uzeli hinders gene flow between populations, even geographically close ones. Although G. uzeli shows limited active flight, its fringed wings allow for its permanence in the air and for wind-driven, long distance dispersal (Lewis, 1997). However, given the distance among sites and the paucity of host plants in between, this would only be possible by transport through saplings or branches of the host plant.

Fixation indices $\left(F_{\mathrm{ST}}: 0.3630\right.$ and $\left.\theta_{\mathrm{B}}: 0.4797\right)$ revealed strong population structure and reinforce the proposal that haplodiploidy, low dispersal capacity, and the process of foundation of new galls influence population structure. A large $F_{\mathrm{ST}}$ of 0.56 was also found by Brito et al. (2012). The low variability observed in all analyses was to be expected given the knowledge about the gall-forming habits of G. uzeli, as well as studies carried out with other haplodiploid organisms. Miranda et al. (2012), using ISSR markers, observed $H_{\mathrm{E}}=0.2616$ and $H_{\mathrm{B}}$ $=0.2573$ for Melipona mandacaia (Hymenoptera: Apidade); Brito et al. (2012), using RAPD markers, found $H_{\mathrm{E}}=0.30$ for G. uzeli; and Crespi (1991), using isozymes, observed an average $H_{\mathrm{E}}$ of 0.058 for four species of thrips, a result similar to that found in a survey of 30 genera of hymenopterans (including wasps, bees, and ants) analyzed with the same technique.

According to Hedrick and Parker (1997), low genetic variation can be a consequence of small effective population size caused by haplodiploidy and of exposition of hemizygotic loci to selection, which would allow these to be removed from the population faster. In the specific case of G. uzeli, although it was first recorded in Brazil in 2011 (Cavalleri et al., 2011), its host plant was introduced in the 1970s (Santos and Ramalho, 1997). However, a number of introductions occurred later, which may have fostered genetic drift, thus, decreasing the gene pool of the population (Frankham et al., 2008). The galling habit of G. uzeli may be another critical factor in the reduction of genetic diversity, as suggested by Van Valen's (1965) hypothesis that more stable environments, such as galls, would favor a decline in heterozygosity.

Hence, geographic distance would not be the determinant factor underlying the observed population structure and genetic diversity in populations of G. uzeli. Such populations are probably influenced by bioecological features (galling habit, dispersal capacity, and haplodiploidy), founder effect, genetic drift, and recent common ancestry, given that a period of a few decades would not be sufficient to differentiate them significantly.

The differences between the data obtained by Brito et al. (2012) and those presented here probably result from the different sampling designs and molecular markers employed. While we sampled 30 individuals per site and individually extracted DNA from each of them, Brito et al. collected 36 individuals and extracted DNA from a pool of four individuals, i.e., nine specimens per site. Thus, variation within populations would tend to decrease and $F_{\mathrm{ST}}$ to increase, as was actually observed in AMOVA results. Furthermore, RAPD markers use prim- 
ers that are shorter than those used for ISSR (10 bp and 16 to $20 \mathrm{bp}$, respectively), thus being less specific, which may bias the data obtained.

Studies such as the current one, which associate molecular analyses to biological data, can support the understanding of the influence of natural history on the dynamics of population structure and genetic diversity, especially in haplodiploid species.

\section{Conflicts of interest}

The authors declare no conflict of interest.

\section{ACKNOWLEDGMENTS}

We thank the Foundation for Research Support of the State of Bahia (FAPESB) for providing a scholarship to A.L.S. Mascarenhas.

\section{REFERENCES}

Ananthakrishnan TN (1993). Bionomics of Thrips. Annu. Rev. Entomol. 38: 71-92.

Brito RO, Artoni RF, Vicari MR, Nogaroto V, et al. (2012). Population structure and genetic diversity analysis in Gynaikothrips uzeli (Zimmerman, 1909) (Thysanoptera: Phlaeothripidae) by RAPD markers. Bull. Entomol. Res. 102: 345-351.

Brunner PC, Fleming C and Frey JE (2002). A molecular identification key for economically important thrips species (Thysanoptera: Thripidae) using direct sequencing and a PCR-RFLP-based approach. Agric. For. Entomol. 4: 127-136.

Cambero-Campos J, Valenzuela-García R, Carvajal-Cazola C, Rios-Velasco C, et al. (2010). New records for Mexico: Gynaikothrips uzeli, Androthrips ramachandrai (Thysanoptera: Phlaeothripidae) and Montandoniola confusa (Hemiptera: Anthocoridae). Fla. Entomol. 93: 470-472.

Cavalleri A, Lima MGA, Melo FS and Mendonça Jr MS (2011). New records of thrips (Thysanoptera) species in Brazil. Neotrop. Entomol. 40: 628-630.

Crespi BJ (1991). Heterozygosity in the haplodiploid Thysanoptera. Evolution 45: 458-464.

Crespi BJ (1993). Sex allocation ratio selection in Thysanoptera. In: Evolution and diversity of sex ratio in insects and mites (Wrensch DL and Ebbert MA, eds.). Chapman \& Hall, New York, 214-234.

Del Cãnizo J (1945). Redescripción de Gynaikothrips ficorum (Marchal) y concepto actual del genero Gynaikothrips Zimmermann, nuevo para la fauna continental Europea (Thysanoptera: Phlaeothripidae). Eos 21: 123-156.

Dobbs TT and Boyd Jr DW (2006). Status and distribution of Montandoniola moraguesi (Hemiptera: Anthocoridae) in the United States. Fla. Entomol. 89: 41-46.

Earl DA and vonHoldt BM (2012). STRUCTURE HARVESTER: a website and program for visualizing STRUCTURE output and implementing the Evanno method. Conserv. Genet. Resour. 4: 359-361.

Evanno G, Regnaut S and Goudet J (2005). Detecting the number of clusters of individuals using the software STRUCTURE: a simulation study. Mol. Ecol. 14: 2611-2620.

Excoffier L, Smouse PE and Quattro JM (1992). Analysis of molecular variance inferred from metric distances among DNA haplotypes: application to human mitochondrial DNA restriction data. Genetics 131: 479-491.

Excoffier L, Laval G and Schneider S (2005). Arlequin (version 3.0): an integrated software package for population genetics data analysis. Evol. Bioinform. Online 1: 47-50.

Falush D, Stephens M and Pritchard JK (2007). Inference of population structure using multilocus genotype data: dominant markers and null alleles. Mol. Ecol. Notes 7: 574-578.

Farong S, Yousheng Z, Huanping Z and Qiong S (1995). The biological characteristics of Gynaikothrips uzeli Zimmerman. J. Northwest For. Coll. 10: 104-108.

Frankham R, Ballou JD and Briscoe DA (2008). Fundamentos de genética da conservação. Sociedade Brasileira de Genética, Ribeirão Preto.

Gonçalves-Alvim SJ and Fernandes GW (2001). Comunidades de insetos galhadores (Insecta) em diferentes fisionomias do cerrado em Minas Gerais, Brasil. Rev. Bras. Zool. 18: 289-305.

Hedrick PW and Parker JD (1997). Evolutionary genetics and genetic variation of haplodiploids and X-linked genes. 
Annu. Rev. Ecol. Syst. 28: 55-83.

Held DW, Boyd D, Lockley T and Edwards GB (2005). Gynaikothrips uzeli (Thysanoptera: Phlaeothripidae) in the southeastern United States: distribution and review of biology. Fla. Entomol. 88: 538-540.

Holsinger KE and Lewis PO (2005). Hickory: a package for analysis of population genetic data v.1.0.4, Department of Ecology and Evolutionary Biology, University of Connecticut.

Kranz BD, Chapman TW, Crespi BJ and Schwarz MP (2001). Social biology and sex ratios in the gall-inducing thrips, Oncothrips waterhousei and Oncothrips habrus. Insect. Soc. 48: 315-323.

Kumm S and Moritz G (2008). First detection of Wolbachia in arrhenotokous populations of thrips species (Thysanoptera: Thripidae and Phlaeothripidae) and its role in reproduction. Environ. Entomol. 37: 1422-1428.

Lewis T (1997). Thrips as crop pests. CAB International, New York, 65-118.

Miller MP (1997). Tools for population genetic analysis (TFPGA), version 1.3. A Windows program for analysis of allozyme and molecular population genetic data, University of Northern Arizona, Flagstaff.

Miranda EA, Batalha-Filho H, Oliveira PS, Alves RMO, et al. (2012). Genetic diversity of Melipona mandacaia Smith 1863 (Hymenoptera, Apidae), an endemic bee species from Brazilian Caatinga, using ISSR. Psyche J. Entomol. 2012: 1-6.

Mound LA, Wang CL and Okajima S (1995). Observations in Taiwan on the identity of the Cuban laurel thrips (Thysanoptera: Phlaeothripidae). J. New York Entomol. Soc. 103: 185-190.

Nei M (1978). Estimation of average heterozygosity and genetic distance from a small number of individuals. Genetics 89: 583-590.

Priesner H (1939). Zur kenntnis der gattung Gynaikothrips Zimm. (Thysanoptera). Mitt Münchner Ent Gesells 29: 475-487.

Retana-Salazar AP (2006). Variación morfológica del complejo Gynaikothrips uzeli-ficorum (Phlaeothripidae: Tubulifera). MES 1:1-9.

Retana-Salazar AP and Sánchez-Chacón E (2009). Anatomía de la agalla em Ficus benjamina (Moraceae) associada a "thrips" (Tubulifera: Phlaeothripidae). Rev. Biol. Trop. 57: 179-186.

Roberts DB (1998). Drosophila: A practical approach. Oxford University Press, Oxford.

Santos E and Ramalho RS (1997). O gênero Ficus (Moraceae) L. em Viçosa-MG. Rev. Ceres 44: 646-665.

Van Valen L (1965). Morphological variation and width of ecological niche. Am. Nat. 99: 377-390.

Wolfe AD (2005). ISSR techniques for evolutionary biology. Methods Enzymol. 395: 134-144.

Wolfenbarger DO (1946). Cuban laurel thrips control on Ficus benjamina. Fla. Entomol. 28: 82-83.

Zietkiewicz E, Rafalski A and Labuda D (1994). Genome fingerprinting by simple sequence repeat (SSR)-anchored polymerase chain reaction amplification. Genomics 20: 176-183. 